\title{
Developing alternative devices to the long-term urinary catheter for draining urine from the bladder
}

\author{
R C L Feneley ${ }^{*}$, J Parkin ${ }^{1}, \mathbf{J ~ S c a n l a n}^{2}$ and M Woolley ${ }^{2}$ \\ ${ }^{1}$ Southmead Hospital, Westbury-on-Trym, Bristol, UK \\ ${ }^{2}$ Faculty of Engineering, University of West England, Bristol, UK
}

\begin{abstract}
The self-retaining urinary catheter is used for long-term drainage of urine from the bladder only as a last resort because of serious associated complications, yet it remains a routine method for managing older and disabled patients with loss of bladder control. Blockage of the catheter from calcified deposits within its lumen is a common occurrence, obstructing the passage of urine and causing an urgent, unpredictable problem for patients, carers and the nursing staff. The need for further research on the subject has been recognized for many years. The SuPort Project aimed to develop an alternative suprapubic urine collection system. This report outlines the approach adopted towards the design and selection of the novel device, the production problems that ensued and the small clinical trial of a modified prototype.
\end{abstract}

Keywords: long-term catheterization of the bladder, suprapubic urethral catheters, new product design

\section{INTRODUCTION}

New product development starts with the recognition of need to address a problem. The self-retaining balloon catheter was first described by Foley in 1929 as 'a hemostatic bag catheter' for use following cystoscopic prostatectomy, a new operation that he introduced [1]. In 1937, Foley reported a modified self-retaining bag catheter, made of latex, for constant drainage of urine from the bladder [2]. Since then, the basic design of the catheter has not changed, and concerns have arisen regarding the risks of allergy to latex. Different materials have been used for catheter manufacture in an attempt to reduce catheter encrustation at the urine/biomaterial interface. The self-retaining urinary catheter is employed universally for short-term or long-term drainage of the bladder, in males and females (Fig. 1).

The catheter can be passed either via the urethra, the natural passage into the bladder, or via the suprapubic route, a direct artificial tract through the lower abdomen above the mid-line symphysis of the pubic bone. Urethral catheterization is normally simple to perform, but repeated catheterization over the long term risks

The MS was received on 4 July 2002 and was accepted after revision for publication on 4 November 2002.

* Corresponding author: Southmead Hospital, Westbury-on-Trym, Bristol BS10 5NB, UK.

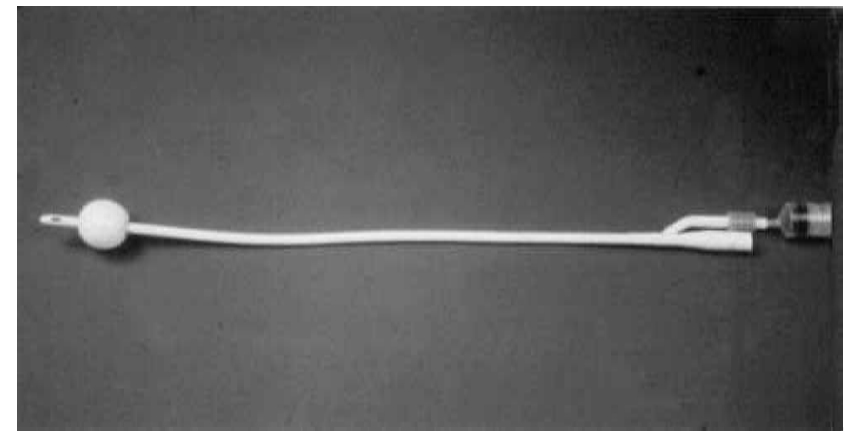

Fig. 1 Conventional urinary catheter with the self-retaining balloon distended

injury or infection to the urethra. In women with neurological conditions such as multiple sclerosis, the catheter can be expelled spontaneously with the balloon distended, causing distension and damage to the urethra; in men, periurethral infection can result in serious complications. The initial introduction of the suprapubic catheter involves a minor operative procedure, normally performed under a local anaesthetic; once the tract into the bladder is established, the catheter can be changed readily. Suprapubic catheterization is considered preferable for nursing those who are bedbound or in wheelchairs, and it is more acceptable for those who wish to remain sexually active. 
Catheterization of the bladder with drainage of urine into a bag provides the most practical and reliable means of collecting and containing the urinary output from patients with loss of bladder control; the total urinary output of an individual normally ranges from 1000 to $1500 \mathrm{ml} /$ day. For those who are cognisant and have good manual dexterity, the bladder may be emptied intermittently by fitting the catheter with a valve. Alternatives to the catheter consist of disposable incontinence pads, worn as a diaper, or the external penile sheath appliance for the male. Incontinence pads have a limited capacity and are difficult to maintain in position, so leakage is common. The condom appliance in the male can be difficult to apply and has a propensity to fall off the penis in older men. None of these devices is discreet, and none presents an attractive alternative to patients.

Long-term use of the catheter, for 28 days or longer, is associated with chronic bacteriuria and a high morbidity which has been recognized for many years [3-6]. Apart from trauma, urinary infection accounts for virtually all the complications associated with long-term catheterization (LTC), including bacteraemia, catheter blockage, bladder stones, periurethral infections, pyelonephritis, septicaemia, bladder cancer and death [7]. A prospective study of a population of nursing home residents established that, whatever their medical status in relation to age, such as heart disease, diabetes or cancer, catheterized patients were 3 times more likely to die within a year than non-catheterized patients [8]. Up to 40 per cent of all nosocomial infections are associated with catheterization, accounting for over 1 million infections in US hospitals per annum [9]. Urethral catheterization initiates bacteriuria at a rate of 3-10 per cent/ day, and within 4 weeks virtually all bladders will be colonized [10]. If urease-producing organisms are present, urea is hydrolysed to ammonia and carbon dioxide, the urine becomes alkaline and crystals of calcium phosphate and ammonium magnesium phosphate nucleate on the catheter surface, causing obstruction to urine drainage and bladder stones [11]. Many different materials have been used for catheter manufacture in an attempt to reduce surface encrustation, but, as yet, currently available types of catheter material have all been shown to be vulnerable to bacterial colonization and encrustation [12]. Encrustation leads to blockage of the catheter, and recurrent blockage is associated with a high incidence of bladder stones; up to 50 per cent of patients with LTC experience episodes of catheter blockage at unpredictable times, day or night, requiring urgent attention [13]. The routine care of these patients, including catheter changes every 6-12 weeks and unplanned emergency calls, occupies an estimated 4 per cent of District Nursing workload $[\mathbf{1 4}, \mathbf{1 5}]$.

In summary, the long-term use of urinary catheters is associated with a high morbidity, and the need to research and develop improved methods of urine collection has been recognized for many years.

\subsection{The SuPort Project}

The SuPort Project (M54), funded by the MedLINK programme, involved a multidisciplinary partnership between the North Bristol NHS Trust, as the clinical centre, the Faculty of Engineering at the University of the West of England, as the academic support, and two industrial partners, namely EMS (Medical) and KeyMed (Medical and Industrial Equipment) Limited. During the course of the first year, the urological division of EMS (Medical) was transferred to Seton, which later became SSL International. The project started on 1 September 1997 and ended on 31 August 2001.

The project set out to design and develop an alternative suprapubic urine collection system for long-term use with the following features:

(a) a suprapubic port providing efficient drainage of urine either continuously into a bag or, if appropriate, intermittently when necessary (Fig. 2). It was to be more aesthetic than the catheter and easier for the patient or carer to manage in the event of any complication such as blockage;

(b) an irrigation/drainage catheter that could be passed through the port by the patient or carer to clear any blockage from encrustation and to remove calcific debris from the bladder, thus reducing the risk of possible bladder stone formation;

(c) access for endoscopic examination for inspection and removal of bladder stones.

The clinical team envisaged a device that would allow the patient or carer to be as independent as possible of routine nursing supervision. The medical/nursing team would be responsible for introducing the device into the bladder and changing it at regular six monthly intervals, but the routine weekly maintenance and hygiene would be undertaken by the patient or carer.

An alternative retention mechanism to the balloon of the conventional Foley catheter was considered

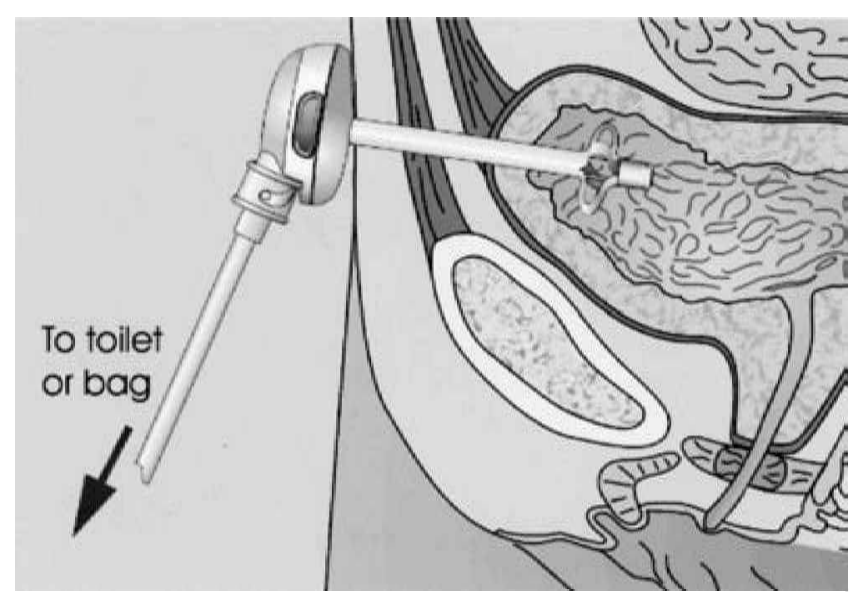

Fig. 2 Concept of a suprapubic device providing continuous or intermittent drainage of the bladder 
preferable. The balloon provides a large surface area for biofilm and crystalline deposits, and the size of the internal lumen of the drainage channel is compromised by the presence of a balloon-filling channel in the wall of the catheter. Moreover, the tip of the catheter with the drainage eyes protrudes beyond the balloon so that stagnant urine remains in the bladder base when the catheter is placed in the urethra and can cause trauma to the bladder wall if passed suprapubically.

\section{METHODS AND MATERIALS}

The engineering design method to be adopted for the suprapubic port presented a major challenge owing to the multiple criteria that had to be considered, including clinical, microbiological, material science and aesthetic factors. A method was required that would address the selection of alternatives when such a variety of needs was presented. An evaluation of practical applications of systematic engineering design techniques was undertaken, and an established method of 'design through selection' was studied, involving a two-stage approach [16]. The design process starts with an agreed list of criteria or 'attributes' as they are called. During the first phase, a large number of concepts are generated, and from these a preliminary selection is made of the alternatives most likely to succeed. These then pass into the second phase, forming the input to a selection-decision support problem (selection-DSP). The selection-DSP uses insight-based 'soft' and science-based 'hard' information to evaluate and rank the feasible alternatives in order of preference, using the established attributes. The highest ranking design is submitted to detailed analysis (Table 1).

This design method of formulating selection-DSPs was enhanced by introducing quality function deployment (QFD) as an auxiliary technique to identify attributes produced via the initial QFD matrix [17]. QFD focuses on developing products in response to customerdefined criteria by collating 'customer' against the necessary 'technical' requirements. Customer requirements are first identified and listed on the left or vertical axis of a 'house of quality' matrix and given a value of relative importance from 1 to 5 . Each item is then broken down into technical attributes to meet the customer

Table 1 Design through selection

\begin{tabular}{ll}
\hline $\begin{array}{l}\text { Phase 1. Generation and } \\
\text { identification of potentially } \\
\text { feasible concepts }\end{array}$ & $\begin{array}{l}\text { Phase 2. Formulation and } \\
\text { solution of selection-DSP }\end{array}$ \\
\hline $\begin{array}{l}\text { Recognition of need } \\
\text { Generation of concepts }\end{array}$ & $\begin{array}{l}\text { Identification and ranking } \\
\text { of attributes } \\
\text { Preliminary selection of } \\
\text { feasible concepts }\end{array}$ \\
& $\begin{array}{l}\text { Evaluation of alternatives } \\
\text { Ranking of alternatives }\end{array}$ \\
& Post-solution analysis \\
\hline
\end{tabular}

requirements and listed on the upper horizontal axis above the central matrix; a relationship value, strong, medium or weak, is then assigned between customer and technical requirements within the matrix. On the lower horizontal or 'how much' axis of the matrix, the relative importance of each technical requirement is indicated by summation of the customer importance value and relationship value. This guides the designers so that product development is focused towards the previously identified customer requirements. The approach to the design by the engineering team was thus structured to form a robust, two-phase, systematic process for the research and development of the suprapubic port [18].

\subsection{Phase 1. Generation and identification of potentially feasible design alternatives}

The need for an improved method of permanent bladder drainage had been established as outlined in section 1 . To establish 'customer' requirements, several group meetings were held, involving members of the partnership with patients, carers and district nursing staff. These led to the formulation of a 'product design specification', a list of general design requirements aimed at overcoming some of the problems associated with LTC. To this were added clinical pass/fail criteria, which listed potential failure modes and the level of risk these might have of morbidity or threat to life. New design concepts were generated by holding brainstorming meetings within the partnership, where ideas and possible solutions were recorded in morphological chart form, producing many possible alternatives. These were each compared with a standard (the Foley catheter), using criteria chosen from the design specification, to identify the options most likely to succeed or 'feasible design alternatives'.

\subsection{Phase 2. Formulation and solution of a selection-DSP and post-solution analysis}

'Customer' requirements were prioritized and then used in a QFD matrix to identify and rank design attributes. This produced a ranking of the specific design attributes in order of importance that could be used for selecting from the alternatives available. The model can then determine the relative importance of customer requirements together with the ranked design attributes. The feasible design alternatives identified in phase 1 are thus mathematically tested to predict the most suitable option. Since the outcome may be sensitive to minor changes in the figures, the final step involves re-examining the calculations, relative weights and ratings to verify the selection.

Medical devices are developed in line with current good design practice (cGDP), with attention to the constraints of the Federal Drug Agency (FDA) and European Medical Devices Directorate (MDD). The 
adopted structured approach ensured justification of the design processes with validation and verification of design, design requirements, risk management, manufacturing methods and test apparatus.

\section{RESULTS}

\subsection{Design}

\subsubsection{Phase 1. Development of feasible design alternatives}

The initial meetings of the multidisciplinary team with patients, carers and nurses in phase 1 established two lists of 'customer', namely patient and medical team requirements (Table 2). From these were developed a set of key design parameters that any product must contain in order to fulfil these demands. At an early stage it was decided the device presented two semi-independent design areas, the 'bladder retention mechanism' and the 'external skin flange', which would be developed in parallel.

The bladder retention mechanism generated a large number of concepts, but these relied heavily on the mechanical properties of a limited range of FDA/MDDapproved biocompatible materials. Preliminary selection produced three alternatives 'most likely to succeed', namely the stretched dome, the tension cage and the drawcord lantern (Fig. 3) which were tested prior to passing into phase 2 of the design process. The designs were validated with respect to the benchmarked bladder retention force of the self-retaining balloon or Foley catheter. A novel anatomical model was constructed for measurement of the retention force of the Foley catheter [19], which was found to be $30 \mathrm{~N}$. This was considered to be in excess of the retention force necessary to avoid

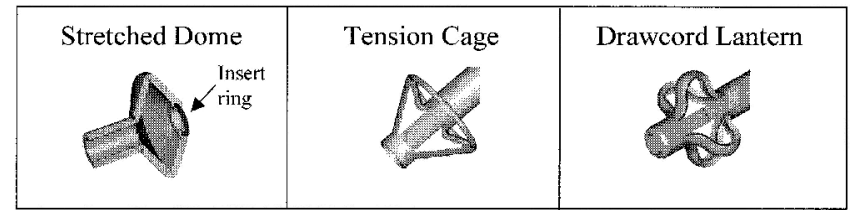

Fig. 3 Alternative designs for the retention mechanism: the stretched dome, the tension cage and the drawcord lantern

inappropriate extraction, and a retention force of $21 \mathrm{~N}$ (66 per cent) was accepted as the target for the new device.

The stretched dome design is so called because the dome is stretched over a metal trocar to reduce its diameter for introduction through the suprapubic tract into the bladder; it was assessed using finite element analysis. This indicated that the force required to deploy the dome would result in the failure of the reinforcing ring (Fig. 3). The concept was finally rejected because the material properties of those certified by the FDA were inadequate to prevent the ring from bursting from the dome during the clinical insertion.

The tension cage was prepared by utilizing computer generated three-dimensional modelling, rapid prototyping (stereolithography) and injection moulding technology. Observations from inspection and handling alone clearly indicated that the cage did not possess an adequate bladder retention force, and this was thus rejected.

Thus, of the three alternatives, only the drawcord lantern was found to be functionally sound, and therefore this was chosen without further analysis by selection-DSP. The design underwent a number of modifications (including increases in the Young's modulus, number, thickness and position of the cage struts) to

Table 2 'Customer' requirements

\begin{tabular}{|c|c|c|c|}
\hline Patient & Requirements & Medical team & Requirements \\
\hline Comfort & $\begin{array}{l}\text { Short/long term } \\
\text { Least amount of discharge } \\
\text { Little interference with } \\
\text { mobility/sleep/clothing }\end{array}$ & Maintenance & $\begin{array}{l}\text { Easy to replace and irrigate } \\
\text { Emergency removal possible } \\
\text { Little maintenance } \\
\text { Low replacement frequency } \\
\text { Good access to bladder }\end{array}$ \\
\hline Appearance & $\begin{array}{l}\text { Acceptable size/colour/shape/ } \\
\text { feel/texture }\end{array}$ & Application & $\begin{array}{l}\text { Any abdominal wall thickness } \\
\text { All ages and bladder dimensions } \\
\text { Any patient condition and size }\end{array}$ \\
\hline Reliability & $\begin{array}{l}\text { Low frequency of replacement } \\
\text { Low risk of leakage } \\
\text { Easy to replace }\end{array}$ & $\begin{array}{l}\text { Surgical } \\
\quad \text { factors }\end{array}$ & $\begin{array}{l}\text { Short and easy insertion time } \\
\text { Few skills and facilities needed } \\
\text { to insert } \\
\text { Low risk of infection }\end{array}$ \\
\hline Complications & $\begin{array}{l}\text { Low risk of blockage/ } \\
\text { infection/stones/bleeding }\end{array}$ & Performance & $\begin{array}{l}\text { Little valve or urethral leakage } \\
\text { Good fixation }\end{array}$ \\
\hline Ease of use & $\begin{array}{l}\text { Ability to locate and grip } \\
\text { drainage tube easily } \\
\text { Easy to clean } \\
\text { Quick to empty }\end{array}$ & Inspection & $\begin{array}{l}\text { Easy to inspect } \\
\text { Wide coverage of inspection }\end{array}$ \\
\hline
\end{tabular}


Table 3 Ranked 'customer' requirements (selected)

\begin{tabular}{llll}
\hline $\begin{array}{l}\text { Relative } \\
\text { importance }\end{array}$ & Patient & $\begin{array}{l}\text { Relative } \\
\text { importance }\end{array}$ & Medical team \\
\hline 23 & Leakage risk & 27 & Ability to remove in emergency \\
20 & Quick to empty & 25 & Positive fixation \\
20 & Resistance to stone formation & 22 & Ease of replacement \\
19 & Ability to clean easily & 21 & Initial surgical skills required \\
16 & Ability to grip drain/irrigation tube & 20 & Low risk of surgical infection \\
15 & Replacement frequency & 19 & Ease of surgical insertion \\
13 & Interference with clothing & 16 & Good access to bladder \\
8 & Interference with mobility & 13 & Tract leakage \\
8 & Minimization with infection & 12 & Valve leakage \\
3 & Colour & 5 & Maintenance facilities required \\
2 & Shape & 1 & Maintenance time required \\
1 & Surface texture & 0 & Initial surgical time required \\
\hline
\end{tabular}

optimize the retention force of the lantern. However, bench tests using the anatomical model quantified a repeatable retention force of only $10.5 \mathrm{~N}$, which was half the benchmark figure, thus raising the question as to whether this would be adequate to avoid the risk of the port being inadvertently pulled out of the bladder.

The skin flange of the port was designed to be lozenge shaped to avoid sharp edges which could cause skin ulceration when the subject moved from the lying to the sitting position. Construction was designed to be in two parts to maximize indwelling duration. One section of the flange, the port assembly, formed the external part of the indwelling port and rested on the skin surface; this was expected to remain in situ for at least 6 months. The other section, the valve assembly, was a removable, replaceable cap that included a valve for intermittent or continuous drainage of the bladder.

\subsubsection{Phase 2. Optimal selection and post-solution analysis}

To select the optimal design for the skin flange from the feasible alternatives, patient and medical team requirements were ranked in order of relative importance and used in a QFD matrix to demonstrate how the design attributes ranked against 'customer' requirements. Examples of the ranking of customer requirements are given in Table 3, where a higher number denotes greater perceived importance.

Table 4 gives a selection of the design attributes in order of relative importance generated from the QFD matrix. The higher the number, the more important this design attribute is to fulfil the specified customer require-

Table 4 Examples of relative importance of design attributes

\begin{tabular}{lc}
\hline Design attribute & Score \\
\hline Duration (working life) of port & 0.545 \\
Flowrate (valve and drainage tube) & 0.494 \\
Ease of valve replacement & 0.430 \\
Interference with mobility & 0.191 \\
Level of dexterity required & 0.143 \\
\hline
\end{tabular}

ments. Table 5 shows how the feasible design alternatives ranked against the 'customer' requirements.

Design alternative 5 was the highest ranked of the four alternatives and thus was selected for the skin flange component to be developed in combination with the 'drawcord lantern' retention mechanism as the final design for the SuPort Project (Fig. 4).

\subsection{Manufacture}

In July 1998, a decision was made regarding the optimal material for the manufacture of the device that was to prove crucial to the outcome of the project. Polyurethane was selected in preference to the original plan to use silicone. Polyurethane was considered to provide both a greater diversity of hardness and ease of bonding, and furthermore a reduced risk of surface encrustation. When the manufacturing stage of the SuPort device was

Table 5 Ranked design alternatives

\begin{tabular}{lll}
\hline Feasible design & $\begin{array}{l}\text { Merit } \\
\text { function }\end{array}$ & Ranking \\
\hline Alternative 5 & 2.056 & 1 \\
Alternative 3 & 1.223 & 2 \\
Alternative 2 & 1.097 & 3 \\
Alternative 6 & 1.038 & 4 \\
\hline
\end{tabular}

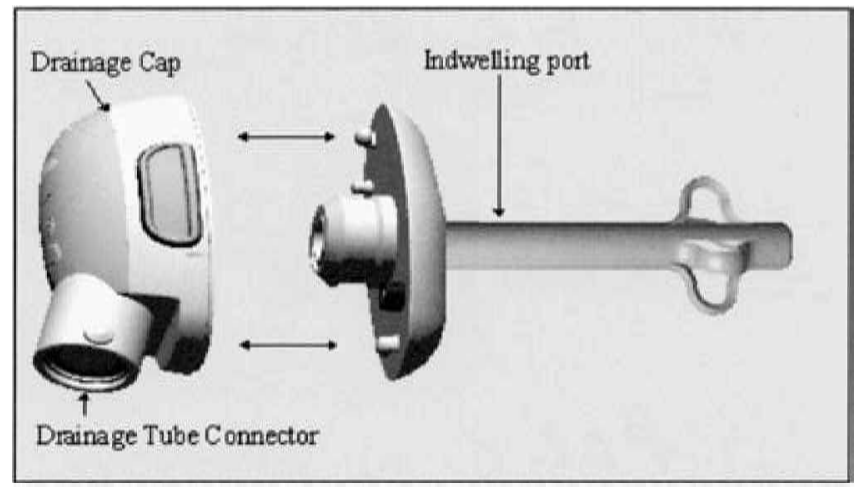

Fig. 4 Final design of the suprapubic port 
reached, a series of problems began to emerge. In January 2000 , the toxicity tests on the adhesive selected to fix the drawstrings for the drawcord lantern were unavailable. This information could not be included in the dossier prepared on the device for submission to the Medical Devices Agency (MDA), and an alternative fixation method was developed using a stainless steel collet. In March 2000, the application to the MDA was rejected because of the lack of appropriate validation data on the sterilization process for the port; the industrial partner had based the validation on their experience of the sterilization procedure used for Nelaton catheters. A bioburden assay was thus undertaken following sterilization of the suprapubic port by gamma radiation.

Injection moulding of the device commenced in June 2000 , and the use of polyurethane presented problems. Component shrinkage occurred during the process, and tooling problems for moulding the skin flange arose. Information became available about the unstable response of polyurethanes to manufacturing processes, with batch-to-batch variation in polyurethane properties, sensitivity to thermal degradation and environmental stress and cracking. In November 2000, evidence was produced that the polyurethanes that had been selected (Chronoflex-CL) required the use of a water-cooled mould and 5 min cooling.

In view of the continuing delays with the manufacture of the skin flange, and theoretical worries involving the in vivo reliability of the retention mechanism, a decision was made to focus on testing the effectiveness of the drawstring lantern retention mechanism.

Therefore, slight modifications were made to allow direct drainage from the device into a catheter drainage system, and finally the product was manufactured in early 2001. After a series of pretrial laboratory assessments, which confirmed that the devices functioned appropriately in vitro, a clinical trial was performed.

\subsection{Clinical trial}

The clinical trial was to involve six patients, with the device in place for variable periods of time, increasing from 1 week for the first patient to 6 weeks for the last. After a period of analysis, a second trial was planned when the device would be inserted for up to 12 weeks. Ethical Committee approval and informed consent were obtained. The clinical trial was terminated after the first four patients because of persistent leakage of urine from the device after a few hours. Three devices were removed after only $12-48 \mathrm{~h}$, the drawstring lantern mechanism apparently functioning satisfactorily, but the fourth device was accidentally pulled out by the patient after becoming unexpectedly disturbed.

The post-trial laboratory assessment concluded that leakage of urine occurred from the skin flange owing to a combination of two problems:
1. A manufacturing error allowed direct communication through the drawcord holes between the internal lumen of the device and the external surface.

2. Creep of the polyurethane material affected the watertight seal between the device and the drainage tubes.

The SuPort Project ended in August 2001. Following the foreshortened clinical trial, further design modifications were made to address the deficiencies identified, but there was no time to produce the final device, subject it to laboratory assessment or repeat the trial using the modified product.

\section{CONCLUSIONS}

The aim of this project was to design a novel suprapubic bladder drainage device, and it was carried out by a multidisciplinary team including engineers, industrialists, clinicians and nurses. The inclusion of patients, carers and community nursing staff in discussions on how the device should both look and function was considered important. Using QFD, their requirements were placed alongside the ideas of the clinical team to become the focus of product development. Although the MedLINK project failed to produce alternative urine collection systems, the design of the SuPort has been patented, and an initial pilot study has been carried out on the retention mechanism of the SuPort device. Also, a considerable amount of information has been accumulated from the studies, and many other goals have been achieved.

These achievements include original research into the anatomical and physiological properties of the suprapubic cystostomy tract, together with the design of a model. The QFD exercise has produced a large volume of requirements from patients and the medical team, highlighting one of the deficiencies of QFD: this amount of information can become difficult to interpret, or cause problems, when there are conflicting customer requirements. The engineering unit has used the information gathered to develop a new system that enhances QFD and may address some of the deficiencies of the current model [20]. Finally, publications in nursing, clinical and scientific journals have highlighted the clinical problems associated with long-term catheterization, together with the need for alternative urine collection systems [21-24].

\section{ACKNOWLEDGEMENTS}

The research and development project outlined in this article was undertaken with the support of the Department of Health and EPSRC under the MedLINK programme. 


\section{REFERENCES}

1 Foley, F. E. B. Cystoscopic prostatectomy: a new procedure; preliminary report. J. Urol., 1929, 21, 289-306.

2 Foley, F. E. B. A self-retaining bag catheter. J. Urol., 1937, 38, 140-143.

3 Bruce, A. W., Sira, S. S., Clark, A. F. and Awad, S. A. The problem of catheter encrustation. Can. Med. Ass. J., 1974, 111, 238-241.

4 Brocklehurst, J. C. and Brocklehurst, S. The management of indwelling catheters. Br. J. Urol., 1978, 50, 102-105.

5 Warren, J. W., Platt, R., Thomas, R. J., Rosner, B. and Kass, E. H. Antibiotic irrigation and catheter-associated urinary tract infections. New Engl. J. Med., 1978, 299, $570-573$.

6 Stamm, W. E. Catheter-associated urinary tract infections: epidemiology, pathogenesis and prevention. Am. J. Med., 1991, 91, 655-715.

7 Warren, J. W. Catheter-associated urinary tract infections. Infect. Dis. Clin. N. Am., 1997, 11, 609-622.

8 Kunin, C. M., Douthitt, S., Dancing, J., Anderson, J. and Moeschberger, M. The association between the use of urinary catheters and morbidity among elderly patients in nursing homes. Am. J. Epidem., 1992, 135, 291-301.

9 Haley, R. W., Culver, D. H., White, J. W., Morgan, W. M. and Emori, T. G. The nationwide nosocomial infection rate: a new need for vital statistics. Am. J. Epidem., 1985, 121, 159-167.

10 Garibaldi, R. A., Burke, J. P., Dickman, M. L. and Smith, C. B. Factors predisposing to bacteriuria during indwelling catheterisation. New Engl. J. Med., 1974, 291, 215-219.

11 McLean, R. J. C., Stickler, D. J. and Nickel, J. C. Biofilm mediated calculus formation in the urinary tract. Cells and Mater., 1996, 6, 165-174.

12 Morris, N. S., Stickler, D. J. and Winters, C. Which indwelling urethral catheters resist encrustation by Proteus mirabilis biofilms. Br. J. Urol., 1997, 80, 58-63.

13 Kohler-Ockmore, J. and Feneley, R. C. L. Long-term catheterisation of the bladder: prevalence and morbidity. Br. J. Urol., 1996, 77, 347-351.

14 Getliffe, K. Catheter blockage in community patients. Nurs. Stand., 1990, 21, 33-36.
15 Roe, B. H. Long-term catheter care in the community. Nurs. Times, 1989, 85, 43-44.

16 Kuppuraji, N., Ittimakin, P. and Mistree, F. Design through selection. Des. Stud., 1985, 6(2), 91-106.

17 Bascaran, E. Design through selection: the use of QFD in the attribute generation process design. Theory and Methodology Conference, 1991, DE-Vol. 31, pp. 195-200.

18 Woolley, M., Scanlan, J. P. and Eveson, W. The use of formal design techniques in the development of a medical device. IMechE International Engineering Design Conference, Brunel University, Uxbridge, 27-29 June 2000.

19 Coveney, V. A. and Gröver, D. An abdominal wall simulator for testing suprapubic urinary catheters. Physiological Measurement. Special edition of Simulation and Modelling Appl. to Med., 2001, 22, 505-516.

20 Woolley, M., Scanlan, J. P. and Eveson, W. Optimising the development of a medical device using formal engineering design techniques and the CODA-system. ICE 7th International Conference on Concurrent Engineering, Bremen, Germany, 26-29 June 2001.

21 Godfrey, H. and Evans, A. Management of long-term urethral catheters: minimising complications. Br. J. Nurs., 2000, 9(2), 74-81.

22 Godfrey, H. and Evans, A. Catheterisation and urinary tract infections: microbiology. Br. J. Nurs., 2000, 9(11), 682-690.

23 Evans, A. and Feneley, R. A study of current nursing management of long-term suprapubic catheters. $\mathrm{Br} . \mathrm{J}$. Community Nurs., 2000, 5(5), 240-245.

24 Evans, A. and Godfrey, H. Bladder washouts in the management of long-term catheters. Br. J. Nurs., 2000, 9(14), 900-906.

\section{REGISTERED DESIGNS}

Registered Design 2088383, Suprapubic port cover. Registered Design 2088384, Suprapubic port.

Registered Design 2088385, Housing for irrigation catheter. 